\title{
Gendered Innovations in

\section{Gendered Innovations in Orthopaedic Science: Show Me the Money}

\author{
Alexandra E. Page MD
}

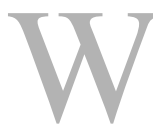

hile passing years increase my cynicism, I still refuse to believe that pecuniary motivations drive medical students to our field. When I made my choice to work in orthopaedics, mired in educational debt (paltry by current standards), the idea of positive cash flow seemed a mirage. Rather, orthopaedic work was exciting, we made most patients better, and the residents and attendings were much happier than those on the general

A note from the Editor-in-Chief:

We are pleased to present to readers of Clinical Orthopaedics and Related Research ${ }^{\circledR}$ the next installment of "Gendered Innovations in Orthopaedic Science” by Alexandra E. Page MD. Dr. Page is a private practice orthopaedic surgeon from San Diego, CA, USA. This year, she will serve as Vice President of the Ruth Jackson Orthopaedic Society. Dr. Page provides commentary on sex and gender similarities and differences in orthopaedics.

The author certifies that neither she, nor any members of her immediate family, have any commercial associations (such as consultancies, stock ownership, equity interest, patent/licensing arrangements, etc.) that might pose a conflict of interest in connection with the submitted article. All ICMJE Conflict of Interest Forms for authors and Clinical Orthopaedics and Related Research ${ }^{\circledR}$ editors and board members are on file with the publication and can be viewed on request. surgery service. Even now, a good day in the operating room can leave me thinking, "Wow, I would pay for the opportunity to have this much fun!" We are fortunate to be compensated for such enjoyable work. And as orthopaedic surgeons repeatedly take the top slot in physician-compensation reports, placing above most other wage-earners in the country, I feel I should be content with my compensation. But sort of like discovering the person sitting next to you on the plane paid USD 300 less for his ticket-perspective is everything. Realizing that the man behind the scalpel in the next room may earn $20 \%$ more for the same work that I do in my room dampens my enthusiasm and can feed cynicism among women in our field.

That men are paid more than women for the same work is not news. But until recently, I naively assumedly that was an issue for other professions.

The opinions expressed are those of the writers, and do not reflect the opinion or policy of Clinical Orthopaedics and Related Research $^{\mathbb{B}}$ or The Association of Bone and Joint Surgeons ${ }^{\circledR}$.

A. E. Page MD $(\varangle)$

Musculoskeletal Health Care Solutions,

3750 Convoy Street, Suite 116, San

Diego, CA 92111, USA

e-mail: alexe.page@gmail.com
However, a few recent studies opened my eyes-Medscape's 2016 annual physician compensation report [13] found that men in orthopaedic surgery earn on average USD 53,000 more than women (USD 448,000 for men versus USD 395,000 for women). Another recent study [8] found a similar gender discrepancy for orthopaedic surgeons in academic practice.

\section{Beyond the Money: Income Satisfaction and Stability}

Take-home pay doesn't even tell the full story. Medscape released survey results on income from a different angle: Are income and assets sufficient to support an orthopedist's life goals [12]? Surprisingly, women demonstrated answers consistent with lower financial security. Among the findings for orthopaedic surgeons, $13 \%$ of men felt they had inadequate income and assets compared with $22 \%$ of women. Sixty-one percent of men, but only $46 \%$ of women, felt they had adequate income and assets; $26 \%$ of men and $30 \%$ of women reported minimal savings to unmanageable debt [12].

Why might this be?

Two gender-related income issues emerge for orthopaedic surgeons: (1) Disparity in income and (2) discomfort 


\section{Gendered Innovations in Orthopaedic Science}

with income and lifestyle stability. Just as making the diagnosis is the first step to effective treatment, identifying the cause is the first step to eradicating the injustice. I offer three possibilities:

\section{Personal Choice—Prioritizing \\ Other Pursuits}

Gender roles outside of the workplace have long been considered a barrier for women. Classically, the "second-shift" work of raising a family and maintaining a household has fallen disproportionately to women. Income disparity resulting from women orthopaedic surgeons prioritizing family or any other nonincome-driving activity over compensated work often represents a willful choice-one that can lead to working fewer hours. Studies $[4,13]$ postulate a correlation between lower income and reduced work hours, including noting that more women $(13 \%)$ identified themselves as working part-time than men (9\%). Could part-time status account for the pay gap in orthopaedics? Even after controlling for hours worked, Curry and colleagues [4] found that only gender and age impacted compensation in orthopaedics. The "part-time excuse" further falls apart when we look at evaluating compensation data for academic physicians in public institutions. Jena and colleagues [8] identified an average pay gap between men and women orthopaedic surgeons of almost
USD 41,000 even after controlling for factors including specialty, faculty rank, and research and clinical revenue productivity [8] -all of which offer a reliable proxy for "hours worked." Bottom line: Women in orthopaedic surgery are producing the work, but not getting the income.

Pervasive, Systemic

Discrimination

Overt discrimination may be uncommon, but subtle bias may permit the persistent factors leading to income disparity. These can include mentors or champions preferentially providing opportunity to men, or even referral patterns that divert more (or more-desirable) cases to men. Perhaps patients perpetrate disparities, with decisions of surgeon choice rooted in social norms associating orthopaedic surgery with the male gender. For example, does the gender difference in surgical caseload reflect such patterns [1]? Regrettably, my takeaway after reviewing studies on discrepancies among academic physicians $[7,8]$ is that systemic discrimination is real. After controlling for factors that should objectively determine salary, a disparity remains.

Regardless of whether the compensation decision-maker is a man or a woman, women are likely to encounter gender biases the moment they voice their concerns about compensation. A study assessing gender differences in compensation negotiations found that evaluators of both genders penalized women more than men for initiating negotiations [2]. Evaluators expressed less willingness to work with candidates of either gender who negotiated, but the effect was five and a half times greater for women. Specifically, the study noted: "Evaluators seem to perceive women who negotiate as too demanding and not nice" [2].

Addressing system-wide bias first requires identification. Most of us carry prejudices we won't admit and may not recognize. The online "implicit bias test" [10] sheds light on our otherwise unforeseen biases (https://implicit.harvard.edu/ implicit). Registrants on the website can choose among myriad tests addressing hidden biases. Inviting (or requiring) institutional leaders to identify their biases can open eyes and combat disparity. From the perspective of the woman with the inferior income, bias may be invisible. Taking the time to read through publically available data could help those in academic institutions. Transparent, codified compensation plans can minimize income disparity in private practices, but the more subtle steerage of patients may be harder to control.

\section{Complacency}

An alternative possibility, potentially encompassing the two explanations 


\section{Gendered Innovations in Orthopaedic Science}

above, is that women either fail to question or fully recognize their own economic value. Our culture identifies financial education and decisions with masculine gender, and this may contribute both to failure of women to demand equal compensation and/or our lower comfort with decisions impacting overall financial security. As an example, even though equal satisfaction with personal income was found for men and women practicing orthopaedic surgery [2], rates of saving and other indicators suggest higher financial insecurity among women [12]. Possible causes for this discrepancy are myriad, but could gender variation in education and knowledge about finances contribute?

Suggesting that income disparity and lower financial security result from women's relative ignorance feels insulting, but it may be a place to identify an intervention. Multiple studies demonstrate gender-based asymmetry of financial literacy $[3,6,11]$. As could be expected, low financial literacy runs parallel with low overall education. But one study [3] found the gender disparity persisted even at advanced levels. For $\mathrm{me}$, as the daughter of a single mother with low financial literacy, a curious mind and an excellent medical education still did not prepare me for understanding the nuances of my professional value.

Complacency may also emerge from the discomfort in discussing compensation. Again, the social gender biases may make women less comfortable with questioning the status quo. One study noted that in contracts without explicit statements that compensation was negotiable, men were more likely to negotiate, whereas women were more likely to accept a lower wage [9]. Interestingly, when the contracts specified negotiable compensation, women were as likely as men to negotiate [9].

\section{What Can Be Done?}

Education and mentoring could potentially diminish complacency. Mentoring seems to be a recurring theme in this column, but with cause: Advice from those further along the same path has huge impact. In the context of finances, simple may be enough. A department chair or older partner asking, "Do you have a financial planner?" could inspire a young woman to self-educate.

As part of career guidance, residency, and fellowship, mentors should apprise women that compensation negotiation is acceptable, if not expected. As suggested earlier, in academic institutions where salaries are publically available, request granular data on compensation that includes gender, age, faculty rank, and research funding. In employed settings, the gender wage gap is a hot topic for Human Resource departments. Requesting transparency on compensation, or at a minimum, specific factors used for calculation, starts the conversation.

I hope passion for the patients and procedures rather than compensation motivate future physicians to choose orthopaedics, although the data clearly suggest that as pay increases, competition for residency slots in those better-compensated fields stiffens, with the dot for orthopaedics sitting comfortably on the upper right of the scatter [5]. Regardless of motivation, men and women train hard and work hard to provide musculoskeletal care. Compensation should be gender-neutral. This is not the reality. But it is only through asking uncomfortable questions that we change behavior.

\section{References}

1. Amoli MA, Flynn JM, Edmonds EW, Glotzbecker MP, Kelly DM, Sawyer JR. Gender differences in pediatric orthopaedics: What are the implications for the future workforce? Clin Orthop Relat Res. 2016;474:1973-1978.

2. Bowles HR, Babcock L, Lai L. Social incentives for gender differences in the propensity to initiate negotiations: Sometimes it does hurt to ask. Organ Behav Hum Decis Process. 2007;103:84-103. 


\section{Gendered Innovations in Orthopaedic Science}

3. Bucher-Koenen T, Lusardi A, Rob Alessie R, van Rooij M. How financially literate are women? An overview and new insights. J Consum Aff. 2016. DOI: 10.1111/joca.12121.

4. Curry EJ, Rieger R, Matzkin EG. Compensation and satisfaction in orthopaedics. Orthop J Harv Med Sch. 2015;16:23-30.

5. Faber DA, Shivam Joshi S, Ebell MH. Research letter: US residency competitiveness, future salary, and burnout in primary care vs specialty fields. JAMA Intern Med. 2016; DOI: 10.1001/jamainternmed.2016.4642

6. Fonesca A, Mullen KJ, Zamarro G, Zissimopoulous J. What explains the gender gap in financial literacy? The role of household decision making. $J$ Consum Aff. 2012;46:90-106.

7. Jagsi R, Griffith KA, Stewart A, Sambuco D, DeCastro R, Ubel PA. Gender differences in the salaries of physician researchers. JAMA. 2012;307:2410-2417.

8. Jena AB, Olenski AR, Blumenthal DM. Sex differences in physician salary in US public medical schools. JAMA Intern Med. 2016. DOI: 10.1001/jamainternmed.2016.3284.

9. Leibbrandt A, List JA. Do women avoid salary negotiations? Evidence from a large-scale natural field experiment. Manag Sci. 2015;61:2016-2024.

10. Lewis VO, Scherl SA, O'Connor MI. Women in orthopaedics-way behind the number curve. $J$ Bone Joint Surg Am. 2012;94:e30.

11. Lusardi A. Financial literacy: An essential tool for informed consumer choice? http://www.nber.org/papers/ w14084.pdf. Accessed November 29, 2016.

12. Peckham C. Medscape orthopedics lifestyle report 2016: Bias and burnout. http://www.medscape.com/ features/slideshow/lifestyle/2016/ orthopedics\#page=22 Accessed January 13, 2016.

13. Peckham C. Medscape orthopedist compensation report 2016. http:// www.medscape.com/features/slideshow/compensation/2016/orthopedics \#page=1 Accessed April 5, 2016. 